U.S. DOE Patent Clearance is not required prior to the publication of this document

$$
\text { DOE/PC/932/8-1/3 }
$$

\title{
FINAL TECHNICAL PROGRESS REPORT
}

for period $9 / 30 / 93$ to $9 / 29 / 96$

on DOE/PETC Grant No. DE-FG-22-93PC93218

"Photochemical Coal Dissolution"

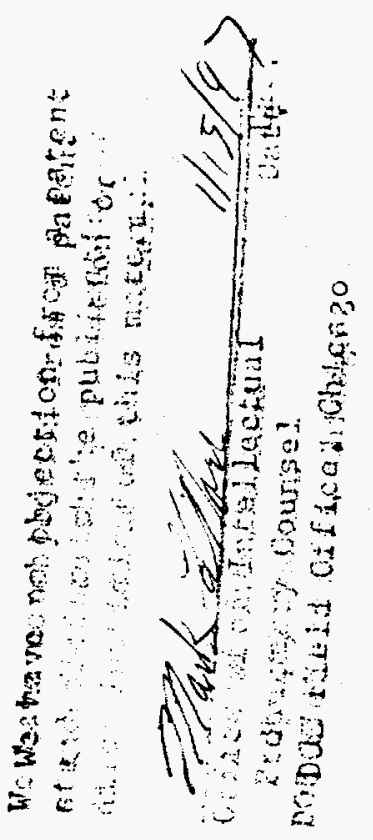

David C. Doetschman, Principal Investigator

Department of Chemistry, State University of New York Binghamton, NY 13902-6016

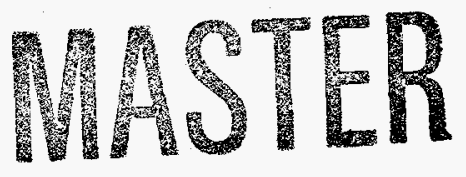




\section{DISCLAMIER}

Portions of this document may be illegible in electronic image products. Images are produced from the best available original document. 


\section{DISCLAIMER}

This report was prepared as an account of work sponsored by an agency of the United States Government. Neither the United States Government nor any agency thereof, nor any of their employees, make any warranty, express or implied, or assumes any legal liability or responsibility for the accuracy, completeness, or usefulness of any information, apparatus, product, or process disclosed, or represents that its use would not infringe privately owned rights. Reference herein to any specific commercial product, process, or service by trade name, trademark, manufacturer, or otherwise does not necessarily constitute or imply its endorsement, recommendation, or favoring by the United States Government or any agency thereof. The views and opinions of authors expressed herein do not necessarily state or reflect those of the United States Government or any agency thereof. 


\section{Summary of Accomplishments}

The highlights of the project were:

- Disproved that appreciable coal residue dissolution occurs photochemically, either directly or when impregnated with $\mathrm{H}$-abstracting or hydrogenating agents at room temperature. ${ }^{1-3}$

- Developed a quantitative characterization of free radical molecular motions in porous solids. ${ }^{4}$

- Determined detailed free radical local structural characteristics in a well-characterized polymeric solid. 5

- Observed solid environment-mediated oxidation of diphenylamine to diphenylnitroxide, and discovered a ground triplet state charge-transfer intermediate in porous solids.

\section{Project Publications}

1. D. C. Doetschman, R. C. Mehlenbacher and O. Ito, Energy Fuels 8, 907 (1994) - contract is continuation of this work.

2. As yet unpublished results.

3. M. Lipson, P. F. McGarry, I. V. Koptyug, H. A. Staab, N. J. Turro and D. C. Doetschman, J. Phys. Chem. 98, 7504 (1994) - detailed consideration of H-abstractor, aryl ketone structurereactivity relation.

4. D. C. Doetschman and G. D. Thomas, Chemical Physics Letters 232, 242 (1995) and previous publication in series.

5. D. C. Doetschman, R. C. Mehlenbacher and D. Cywar, Macromolecules 29, 1807 (1996) polymer principles generally applicable to coal chemistry and structure.

6. R. P. Borkowski, D. C. Doetschman, J. D. Fox and C. Gargossian, "Oxidation of Diphenylamine to Diphenylnitroxide in Faujasite Zeolite Studied by Electron Paramagnetic Resonance," Chemical Physics, submitted for publication.

A number of scholars received training in fossil fuel-related science and research under this grant:

\section{Graduate Students}

Mr. Jack Fox, Chemistry M.S., December 1996.

Dr. Randy Mehlenbacher, Chemistry Ph.D., May 1995.

Mr. Gregory Thomas, Chemistry Ph.D. student.

Miss Jing Wei, Chemistry M.S., May 1996. 


\section{Undergraduate Students}

Miss Monisha Bhanote, Chemistry B.S., May 1996.

Mr. Craig Gargossian, Chemistry B.S., May 1996.

Mr. Will Maxson, Summer 1994, DOE Summer Intern

Visiting Scholar
Professor Raymond Borkowski, King's College, Wilkes-Barre, PA, September 1994 - May 1995.

\section{Scientific Report}

The Photochemical Reactor

A flowing solvent photochemical reactor was designed, built and tested. A modified ACE photochemical reactor, lamp and power supply were employed. They were modified to accommodate a silica column-constrained dispersed coal sample and a solvent flowing through the silica/coal column to sweep away coal extract. Before each experiment the column was packed with the mixture of silica and coal in the annular space around the lamp. A reflective aluminum surface (foil) reflected any light-transmitted through the column for multiple passes back through the sample. A variable speed Rainin Rabbit Plus peristaltic pump was interfaced to an IBM XT computer via a Gilson RS232/RS422 converter. The purpose of the computer control was to vary the speed of the pump so as to control the absorbance of the solution of coal extract in the solvent. Absorbances at a chosen wavelength were measured by a Spec 21 spectrophotometer with a flow cell connected to the column effluent port. A signal proportional to \% transmittance from the Spec 21 was delivered to the computer through a Keithley DAS $801 \mathrm{~A} / \mathrm{D}$ plug-in in the computer. The analysis of the Spec 21 signal and control of the pump speed was based on a QuickBasic computer program written by us. A block diagram of the system is shown in Figure 1.

The experiments with the flowing solvent coal photochemical reactor were successful in the sense that appreciable photochemistry was observed. However, the experiments did not show significant photochemical extraction of the coal beyond what could be thermally extracted. Rather, several types of solvent and solvent-sensitizer photochemistry were observed and carefully characterized in order to minimize or avoid their effects.

\section{Interfering Pyridine Photochemistry}

Experiments led to the conclusion that pyridine sensitizing solvent under irradiation from the medium presure $\mathrm{Hg}$ arc lamp of the photochemical extractor undergoes undesirable photochemistry. Pyridine photochemistry under similar conditions has been observed by Wilzbach 
\& Rausch. ${ }^{1}$ The chemistry was shown to take place by conversion to Dewar pyridine. The yellowbrown solid, melting or decomposing above $350^{\circ} \mathrm{C}$, is obtained by us in maximum yield when water is added to the traces already present in pyridine. According to $\mathrm{x}$-ray diffraction, the material is amorphous and elemental analysis demonstrates a $\mathrm{C} / \mathrm{N}$ ratio equal within experimental error to that of pyridine itself. X-ray microprobe analysis indicates that the balance ( $\leq 40 \%$ by weight) is oxygen. Previous work demonstrated that Dewar pyridine hydrolyzes in the presence of water but did not find the polymeric product ${ }^{1}$ indicated by our results.

The encounter with undesirable pyridine solvent photochemistry demonstrated the need for precautionary filtering of the irradiating light. In order to reduce this type of pyridine photochemistry, the photochemical reactor was outfitted with a Vycor optical filter. While the difficulties were appreciably reduced, Dewar pyridine formation, hydrolysis and polymerization continue to coat the optical surfaces, unacceptably blocking light passage.

\section{Interfering THF Photochemistry}

In order to work in a solvent with negligible absorbance of Vycor-transmitted light, experiments were performed in tetrahydrofuran (THF) from which the manufacturer's inhibitor was removed immediately before use. Figure 2 shows the photoproduct yields by weight from $80 \mathrm{~min}$ of about $8 \mathrm{ml} / \mathrm{min}$ THF flow through our reactor loaded with $200 \mathrm{mg}$ of Pocahontas \#3 coal residue. Blanks were also run with no coal. Yields that were greatly in excess of total residue weight were observed when air was not purged from the system. The presence of coal exhibits an inhibiting effect on what clearly must be solvent degradation. The coal inhibiting power on a weight basis is about one-half that of the manufacturer's inhibitor, 2,3-di-tert-butyl para hydroxytoluene (BHT). GC/MS and ${ }^{13} \mathrm{C},{ }^{1} \mathrm{H}$ NMR analyses of the photoproduct indicate THF ring-opening rearrangements. Similar products were observed from the air-purged experiments. The marked dependence on oxygen concentration suggests peroxide chemistry. However, only minor peroxide product content was indicated and the yields were in at least ten-fold molar excess of the most generous estimates of dissolved or adsorbed oxygen. Thus peroxides, if involved, must be involved catalytically or are recycled, e.g. from decomposition of light-absorbing organic peroxides. It is not clear what species absorbs the light in the absence of coal residue.

The differences in THF steady-state photolysis light transmission at $350 \mathrm{~nm}$ through the solution exiting the reactor are illustrated in the long-time limits approached in Figure 3. The greater difference in the absence of coal residue is in agreement with the hypothesis that coal is an inhibitor of the THF peroxide formation. As one mode of BHT inhibition is via hydrogen donation, it is plausible that hydrogen donors in the coal residue act as comparably powerful inhibitors. Figure 3 also illustrates how the absorbence (calculable from transmittance) time-dependence at any 
chosen wavelength can be acquired with the computer-interfaced spectrophotometer and with the pump speed controlled via the computer-interfaced solvent pump of the photochemical reactor system.

\section{Triplet Benzophenone $\mathrm{H}$-Abstraction}

In order to explore photosensitized coal extraction reactions, an approximately $50 \%$ transmittance (@350 nm) solution of benzophenone (BP) in n-hexane was flowed through the photochemical reactor. The bottom trace of Figure 4 is a blank showing the purely physical silica affinity of benzophenone on the reactor column, due to the transient benzophenone concentration caused by the benzophenone initially adsorbed onto the column of the reactor. When the system was irradiated with coal residue on the column, the third (from top) trace was observed, showing an initial increase in transmittance, followed by a subsequent continuous drop with time. In the absence of coal residue, as shown in the second (from top) trace, the initial increase is observed without the subsequent drop.

NMR indicates that in the absence of coal residue, benzpinacol and $350 \mathrm{~nm}$ light-absorbing products of intermediate hexyl radicals are being formed. (It is known that the benzopenone triplet state quenching by hexane is small but not always negligible.) With coal residue on the column, the progressive appearance in solution of more highly colored material suggests that coal residue is competing to an observable extent with solvent for benzophenone attack and is being solubilized. However, on a mass basis the weights of extract were not significant.

Acetonitrile was then chosen as a solvent inert to triplet benzophenone hydrogen abstraction, although it is admittedly a poor thermal coal extraction solvent.

The benzophenone concentration was adjusted to about $50 \%$ transmission $(50 \% \mathrm{~T})$ through the light path of the reactor. Negligible changes in effluent light transmittance were observed for all four coal residues when the pyrex filter was employed. Correspondingly, no significant photoextraction yields were found relative to the corresponding thermal extractions. However, when the quartz filter was employed, $20-25 \% \mathrm{~T}$ decreases were observed in the effluents from the coal residues. A subsequent run without coal demonstrates that under these conditions, benzophenone is reacting to form a more strongly light absorbing product. Weight measurements show that insoluble benzophenone decomposition product material is also being retained on the column. Some fairly universally insoluble, yellow-orange-brown deposits were also present in all BP solution experiments. The transmittance traces for these experiments are shown in Figure 5.

In summary, these experiments demonstrate that coal residues are inert to extraction with benzophenone sensitizer in acetonitrile. On the other hand, photoextraction in acetonitrile is readily 
detected optically with direct irradiation of the residues from the low and medium rank bituminous coals and with pyridine sensitization of all of the residues. However, the corresponding extraction yields by weight are negligibly small.

Photolysis experiments on BP-swelled coal residues were designed to maximize BP hydrogen abstraction from the coal residue and to minimize the BP side reactions. The BP: coal residue ratio by weight was $1: 1$. Conditions in the BP-filled coal pores should maximize the interactions between coal and $\mathrm{BP}$, while minimizing the relative degree of interaction between $\mathrm{BP}$ molecules. These BP-swelled coal samples were irradiated through a quartz light filter for $84 \mathrm{~min}$. in the absence of solvent in the photochemical reactor, while suspended on the reactor silica column. The samples were extracted for $84 \mathrm{~min}$. with acetonitrile through the transmittance monitoring system. A trace of one of these runs is compared in Figure 6 with a blank run with a pyrex light filler whose transmitted light does not appreciably excite BP. While there are subtle decreases in the $350 \mathrm{~nm}$ transmittance of the extract over the BP extract in the blank, these do not represent extraction of significant amounts of the coal residue according to yields by weight.

In conjunction with these BP-swelled coal residue experiments, we performed a series of collaborative experiments to learn how deformations of the BP structure, such as may occur in the pores of the coal, can affect the photophysical and photochemical properties of BP. ${ }^{2}$ We also investigated the rotational diffusional motion of organic spin-probe species in porous solids, indicating the types of behavior that might be expected in other porous media such as coals and coal residues. ${ }^{3}$

Photolysis experiments on BP-swelled coal residues were designed to maximize BP hydrogen abstraction from the coal residue and to minimize the BP side reactions. The BP: coal residue ratio by weight was 1:1. Conditions in the BP-filled coal pores should maximize the interactions between coal and $\mathrm{BP}$, while minimizing the relative degree of interaction between $\mathrm{BP}$ molecules. These BP-swelled coal samples were irradiated through a quartz light filter for 84 min. in the absence of solvent in the photochemical reactor, while suspended on the reactor silica column. The samples were extracted for $84 \mathrm{~min}$. with acetonitrile through the transmittance monitoring system. A trace of one of these runs is compared in Figure 6 with a blank run with a pyrex light filler whose transmitted light does not appreciably excite BP. While there are subtle decreases in the $350 \mathrm{~nm}$ transmittance of the extract over the BP extract in the blank, these do not represent extraction of significant amounts of the coal residue according to yields by weight.

\section{Other Experiments}

In the experiments where pyridine was employed as a photochemical reagent, the pyridine concentration was likewise adjusted to about 50\% transmission $(50 \% \mathrm{~T})$ through the light path of 
the reactor at $320 \mathrm{~nm}$. Small decreases of $5-20 \% \mathrm{~T}$ were observed in the effluents from the coal residues. However, these effluents contain no significant photoextraction yield by weight relative to the corresponding thermal extractions.

We did a series of experiments using tetralin in conjunction with direct irradiation of the coal residues. We observed almost quantitative consumption of a mixture of dissolved polycondensed aromatics in tetralin where the aromatics are selectively photoexcited through the pyrex filter. The aromatics initially present in tetralin have about $10 \% \mathrm{~T}$. When irradiation begins, the aromatics in the effluent are evidently hydrogenated by tetralin. The aromatic absorbance is almost eliminated probably due to the formation of hydroaromatics.

Minor transmittance changes in (neat) tetralin coal photoextraction experiments were observed. Like the benzophenone solution experiments, the changes $(+7.0$ to $7.5 \%)$ were similar for the different coals examined and the photochemical blank experiment with no coal present gave a similar increase in transmittance. Tetralin photochemistry was similarly, conclusively implicated. Technical grade tetral is known to contain naphthalene as the major impority. Thus we questioned whether the increase in transmittance might have resulted from the photochemical hydrogenation of naphthalene by the predominant tetralin. NMR experiments and standard tetralin purification methods disproved this hypothesis, suggesting that only minor tetralin imporities are being removed by photolysis. The absence of naphthalene photohydrogenation by tetralin was further confirmed in NMR studies of the irradiation of 3:1 W/W tetralin-naphthalene solutions. Once again the degree of extraction by weight was not significant.

We also pursued our coal free radical related program of developing means of analyzing the powder EPR spectra of randomly oriented free radicals in polymeric solids. 4 In this study the propagating free radical spectra in polymethyl methacrylate and the mid-chain radical rearrangement product of the propagating radical in polymethyl acrylate were observed and anlyzed in detail. Conformational distributions in the polymer proved to be important in understanding the spectra.

\section{Diphenylamine Oxidation in Porous Solid}

The five months of the research grant remaining after the coal photoextraction experiments were completed were spent on a variety of experiments dealing with charge-transfer phenomena in porous media. The rationale was that these studies might lay the groundwork for developing a photochemical charge-transfer reaction scheme for coal solubilization. After exploring such charge-transfer complexation as tetracyanobenzene, tetracyanoanthracene and tetracyanoethylene electron acceptors with a series of aromatic electron donors with various degrees of ring 
condensation and such as several ketone-amine electron donor-acceptor systems, we focused our attention on a novel zeolite cage mediated aromatic amine oxidation.

Here we summarize this study of the oxidation of diphenylamine to diphenylnitroxide in faujasite zeolite by electron paramagnetic resonance (EPR). A preprint of a manuscript submitted for publication ${ }^{5}$ is attached to this report as an appendix.

Oxidation of diphenylamine to diphenylnitroxide, in neutral, K-exchanged, X-type faujasite zeolite (KX) has been observed. The oxidation, as assessed by the intensity of the diphenylnitroxide EPR spectrum, is favored in $\mathrm{KX}$ in comparison with diphenylamine doped into $\mathrm{X}$ type faujasite zeolites exchanged with $\mathrm{Li}, \mathrm{Na}, \mathrm{Rb}$ or $\mathrm{Cs}$. Similar experiments with analine gave no detectable free radical signal and triphenylamine did not load into the zeolite from hexane solution. The weakly allowed $\Delta \mathrm{m}_{\mathrm{s}}= \pm 2$ half-field peak of a triplet state EPR spectrum with $\sqrt{\mathrm{D}^{2}+3 \mathrm{E}^{2}} / \mathrm{g}_{\mathrm{e}} \beta_{\mathrm{e}}=1200 \pm 150 \mathrm{G}$ is observed to correlate in intensity. The triplet spectrum is attributed to molecular oxygen probably immobilized at a Lewis acid site in the zeolite. Alternatively the spectrum is a charge-transfer triplet state between the diphenylamine donor and a Lewis acid site acceptor that are particularly well-matched in energy in the $\mathrm{K}$-exchanged zeolite. We propose that electron transfer from diphenylamine to the oxygen sites occurs, giving rise to $\mathrm{O}_{2}{ }^{-}$ which subsequently reacts with transient diphenylamine cation to form diphenylnitroxide. The mechanism implies that $\mathrm{OH} \cdot$ is trapped and stabilized by the zeolite, although $\mathrm{OH} \cdot$ is not observed by us in the EPR spectrum. The temperature dependence of the diphenylnitroxide EPR spectrum indicates a restricted degree of molecular motion in the zeolite cages.

\section{Acknowledgment}

The authors acknowledge the support of the Department of Ehergy under contract DE-FG22-93PC93218. 


\section{References}

1. K. E. Wiltzbach and D. J. Rausch, J. Amer. Chem. Soc. 92, 2178 (1970).

2. M. Lipson, P. F. McGarry, I. V. Koptyug, H. A. Staab, N. J. Turro and D. C. Doetschman, J. Phys. Chem. 98, 7504 (1994).

3. D. C. Doetschman and G. D. Thomas, Chemical Physics Letters 232, 242 (1995).

4. D. C. Doetschman, R. C. Mehlenbacher and D. Cywar, Macromolecules 29, 1807 (1996).

5. R. P. Borkowski, D. C. Doetschman, J. D. Fox and C. Gargossian, Chemical Physics, submitted for publication. 
Figures

1. Schematic diagram of the photochemical reactor system.

2. Dependence of photoproduct in THF solvent on the presence and absence of Pocahontas \#3 coal residue and on the presence and absence of air $\left(\mathrm{O}_{2}\right)$.

3. Extract optical transmission at $350 \mathrm{~nm}$ as functions of time in the presence and absence of light and in the presence and absence of Pocahontas \#3 coal residue in the presence of air. Flow rate was held constant.

4. Column effluent optical transmission versus time with irradiated Pocahontas \#3 coal residue in the presence and absence of sufficient benzophenone to give $55 \% \mathrm{~T}$ at $350 \mathrm{~nm}$. A similar pair of experiments done without the coal was done with and without irradiation. No optical filters were employed and flow rate was held constant.

5. Column effluent $\% \mathrm{~T}$ at $350 \mathrm{~nm}$ versus time for a selection of coal residues treated with a benzophenone solution in acetonitrile sufficient to give a $50 \% \mathrm{~T}$ solution at $350 \mathrm{~nm}$. A blank (no coal) run is also presented. Flow rate was held constant.

6. Column effluent extracted thermally from a sample of benzophenone-swelled Pittsburgh \#8 coal residue previously irradiated through a quartz filter. The pyrex experiment is a blank in which no direct absorption of light by benzophenone takes place. Flow rate is constant. 


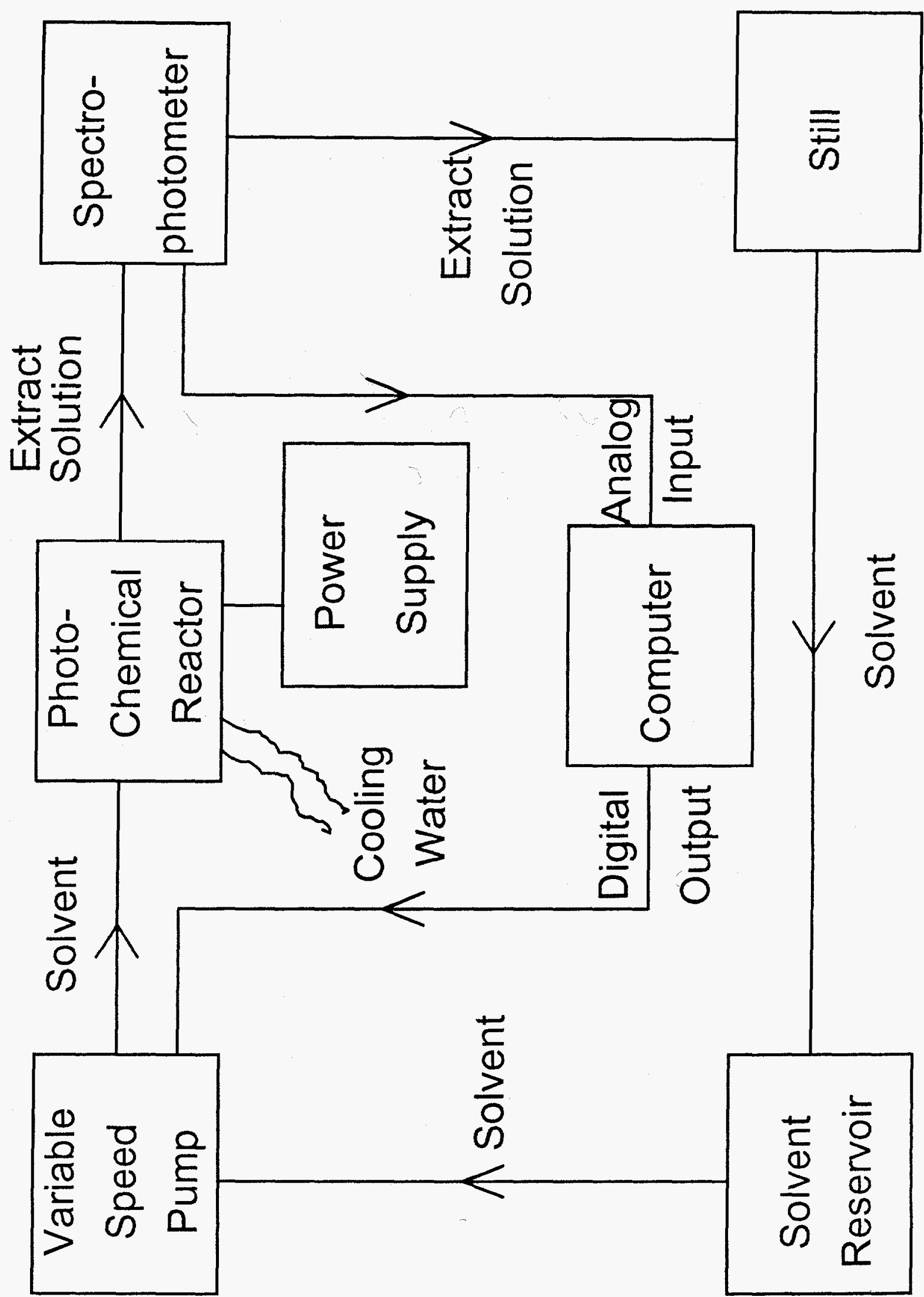




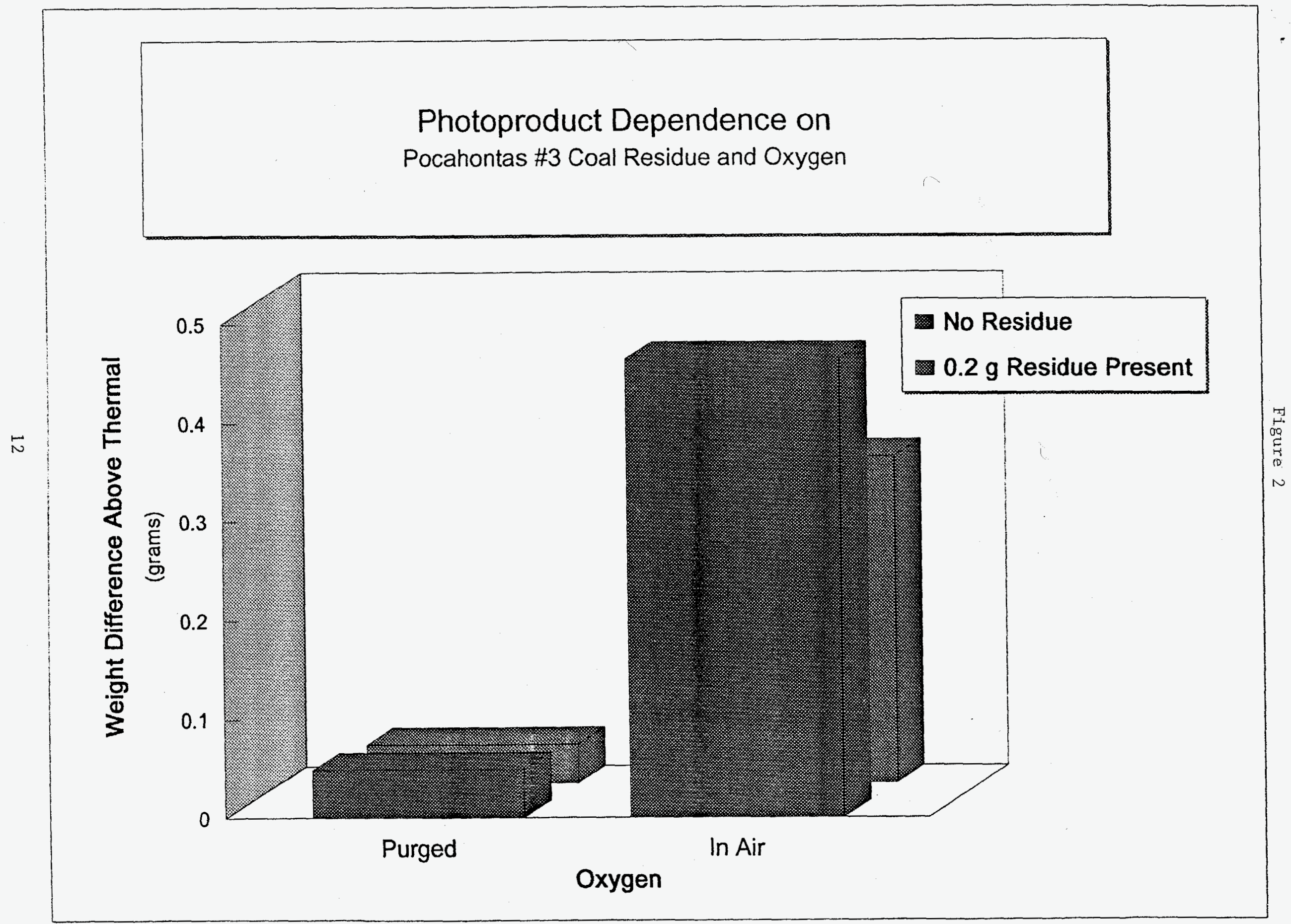




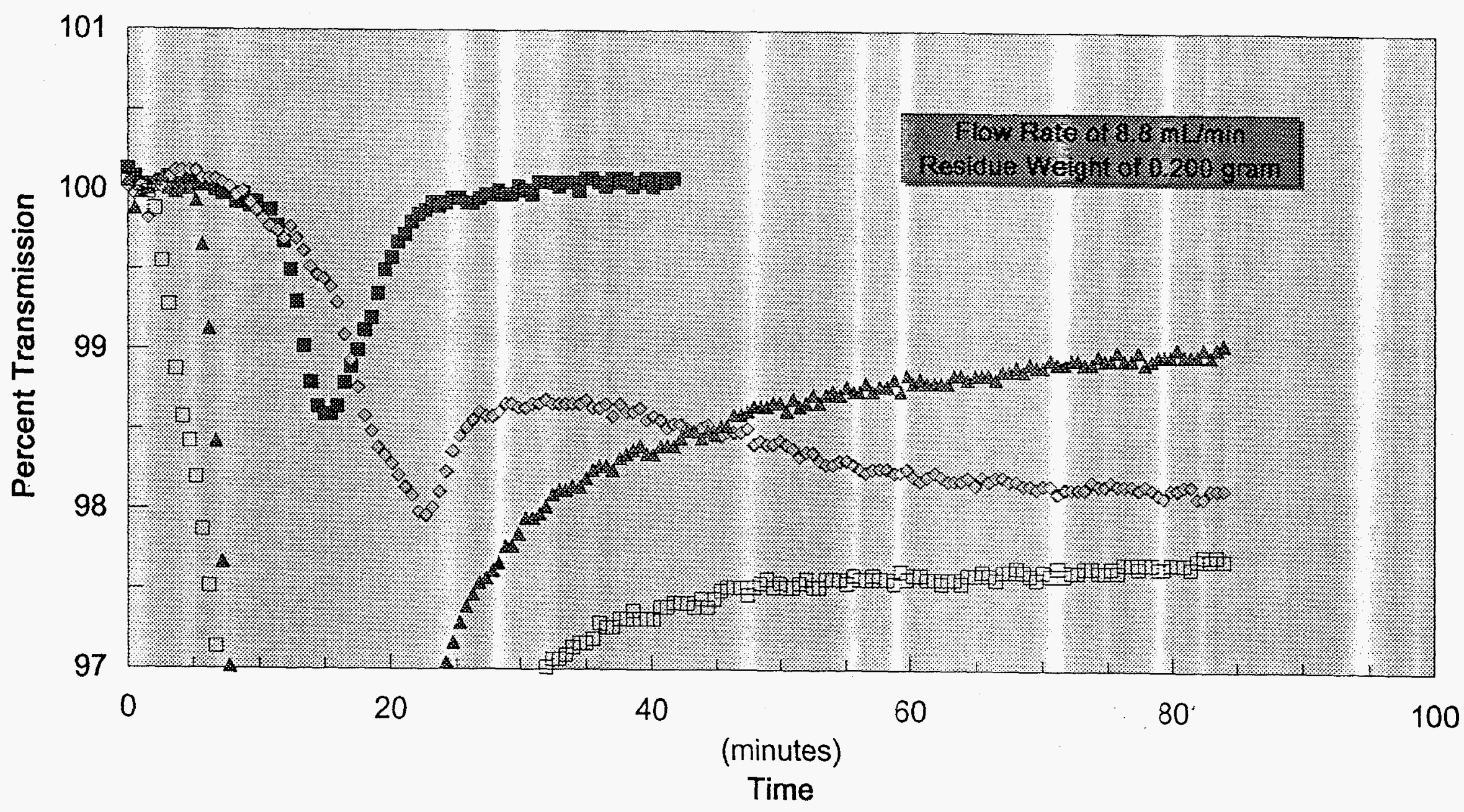

- Blank

^ Coal Residue
- Blank \& Light

口 Coal Residue \& Light 


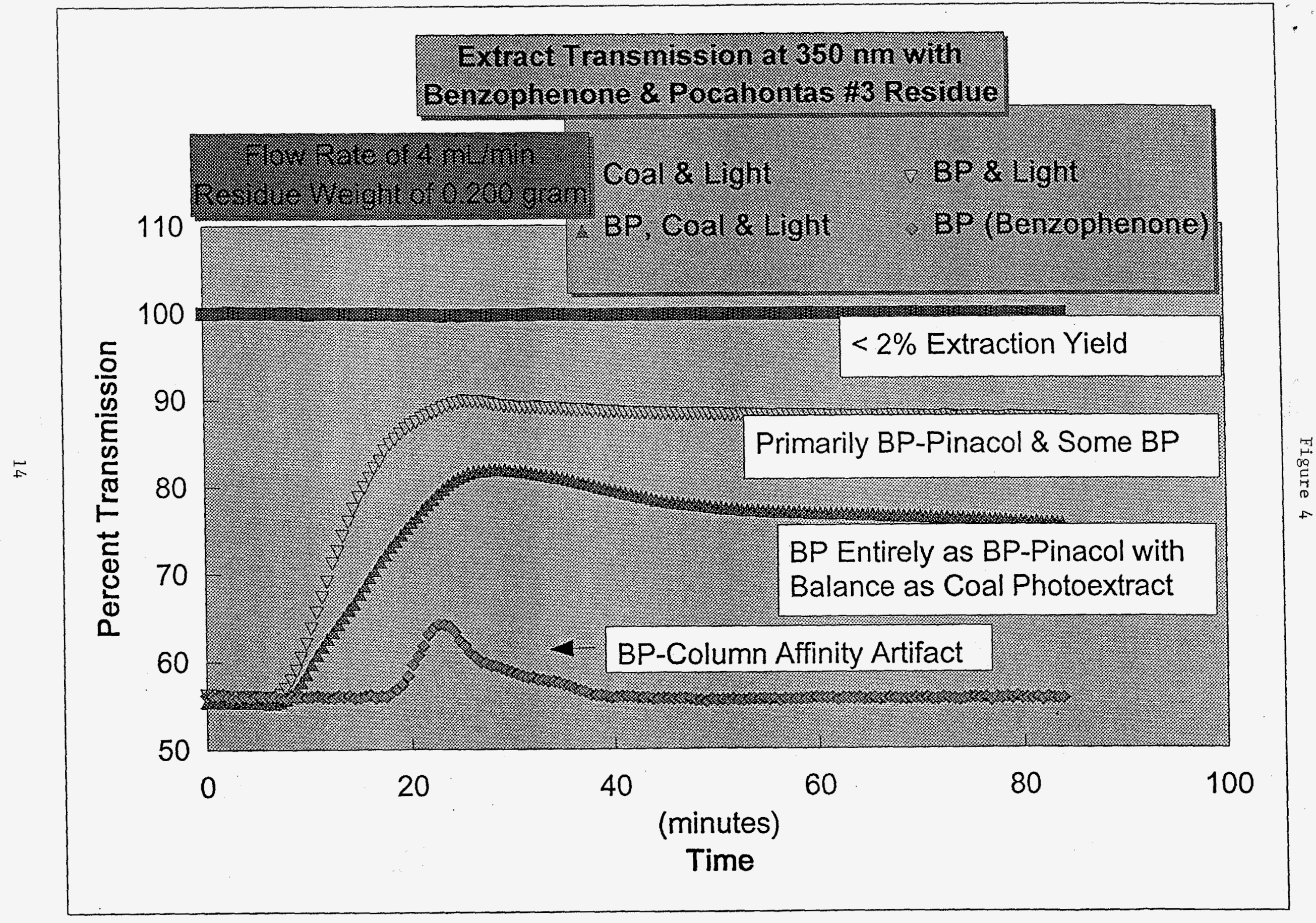


Figure 5

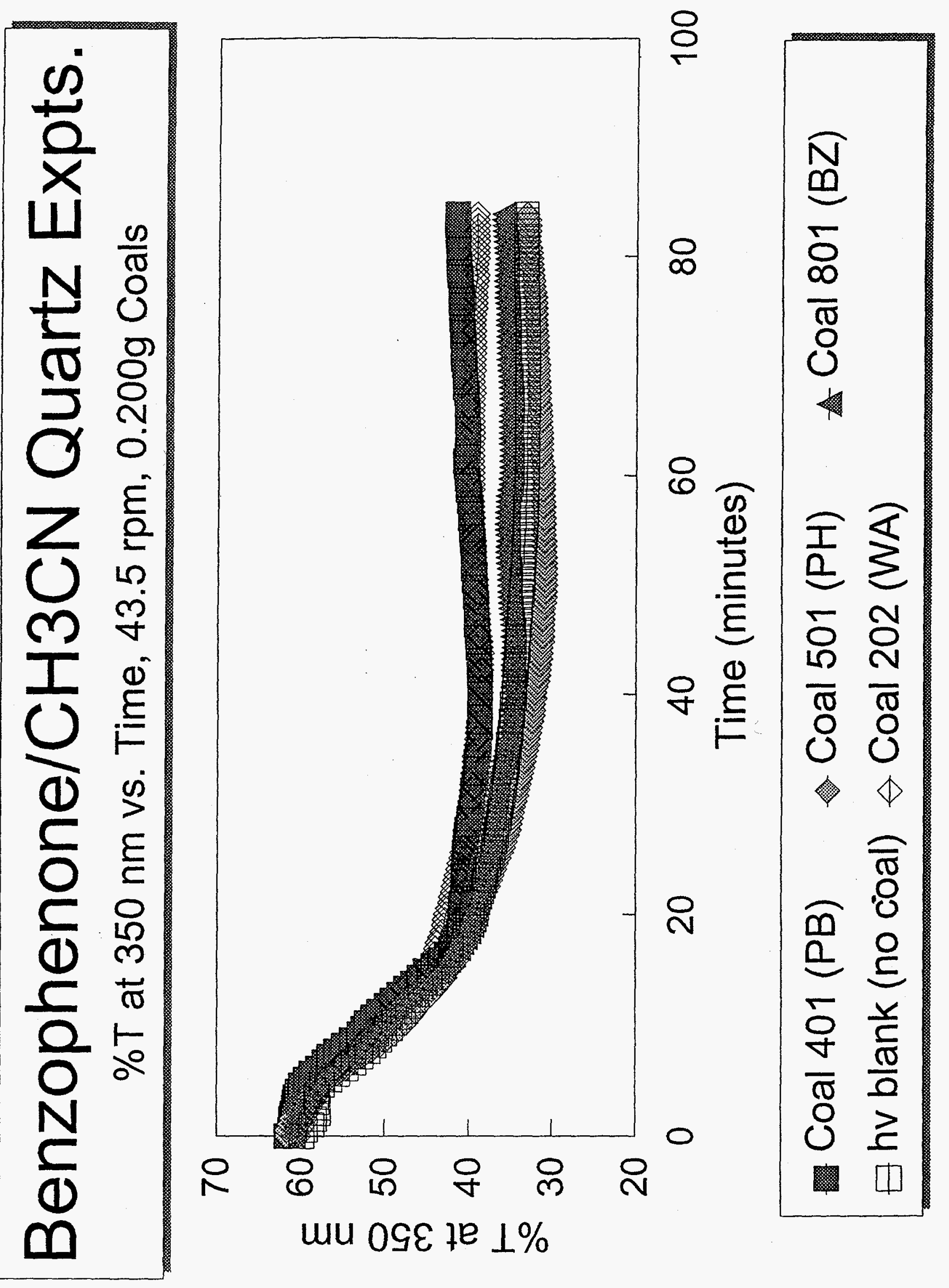


Figure 6

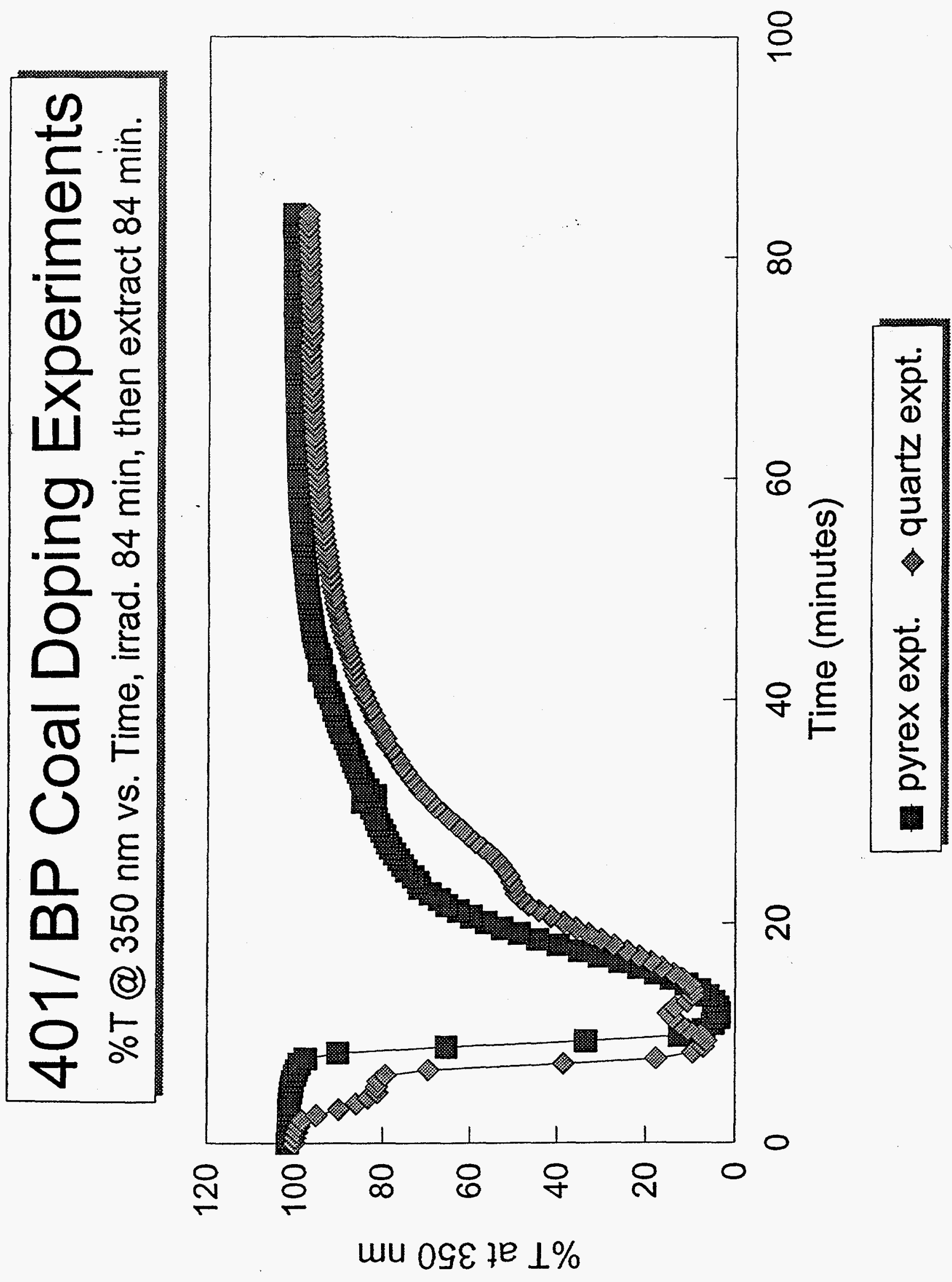


Oxidation of Diphenylamine to Diphenylnitroxide in Faujasite Zeolite Studied by Electron Paramagnetic Resonance

R. P. Borkowski, ${ }^{\dagger}$ D. C. Doetschman, ${ }^{*}$ J. D. Fox and C. Gargossian, Department of Chemistry, Binghamton University, State University of New York, Binghamton, New York, USA 139026016

\begin{abstract}
Oxidation of diphenylamine to diphenyl-nitroxide in neutral, K-exchanged, X-type faujasite zeolite (KX) has been observed. The oxidation, as assessed by the intensity of the diphenylnitroxide electron paramagnetic resonance (EPR) spectrum, is favored in $\mathrm{KX}$ in comparison with diphenylamine doped into X-type faujasite zeolites exchanged with $\mathrm{Li}, \mathrm{Na}, \mathrm{Rb}$, or Cs. Similar experiments with analine gave no detectable free radical product. The weakly allowed $\Delta \mathrm{m}_{\mathrm{s}}= \pm 2$ half-field peak of a triplet state EPR spectrum with $\sqrt{\mathrm{D}^{2}+3 \mathrm{E}^{2}} / \mathrm{g}_{\mathrm{e}} \beta_{\mathrm{e}}=1200$ $\pm 150 \mathrm{G}$ is observed to correlate in intensity with the diphenylnitroxide EPR intensity. The triplet spectrum is attributed to molecular oxygen probably immobilized at a Lewis acid site in the zeolite. We propose that electron transfer from diphenylamine to these sites occurs, giving rise to $\mathrm{O}_{2}{ }^{-}$which reacts subsequently with diphenylamine cation to form diphenylnitroxide. The mechanism implies that the $\mathrm{OH}^{*}$ is trapped and stabilized by the zeolite. The temperature dependence of the diphenylnitroxide EPR spectrum indicates a restricted degree of molecular motion in the zeolite cages.
\end{abstract}

\footnotetext{
${ }^{\dagger}$ On leave from King's College, Wilkes-Barre, PA.
} 


\section{Introduction}

Partial oxidation of organic substrate in zeolite matrixes is of considerable current interest. The chemistry involves charge-transfer processes and superoxy or peroxy species. ${ }^{1-4}$ Electrontransfer from methylviologen or diquat to $\mathrm{O}_{2}$ in the sodium-exchanged Y-faujasite zeolite $(\mathrm{NaY})$ gives superoxide, $\mathrm{O}_{2}{ }^{-5,6}$ In a number of these studies the cation formed from the organic substrate acts as a Bronsted acid, donating a proton to the superoxide. ${ }^{1-4}$

The triphenylamine cation $\left(\mathrm{C}_{6} \mathrm{H}_{5}\right)_{3} \mathrm{~N}^{+}$is observed by EPR to be formed when triphenylamine $\left(\mathrm{C}_{6} \mathrm{H}_{5}\right)_{3} \mathrm{~N}$ is put in contact with decationated $\mathrm{Y}$ zeolite, formed from the calcining of ammonium ion-exchanged $\mathrm{Y}$ zeolite, $\mathrm{NH}_{4} \mathrm{Y}$ above $400^{\circ} \mathrm{C}$ under a vacuum. 7,8 A stronger signal was observed in acid mordenite $\mathrm{HM}$ when it is doped with analine. ${ }^{8}$ When oxygen is admitted to these analine samples, a strong $\mathrm{O}_{2}{ }^{-}$EPR spectrum is observed characteristic of its interaction with a zeolite ${ }^{27} \mathrm{Al}$ nuclear spin $(\mathrm{I}=5 / 2) .{ }^{8}$ It is proposed that the $\mathrm{O}_{2}^{-}$is stabilized at a deoxygenated $\mathrm{Al}$ .. Si Lewis acid site in the calcined, decationated $\mathrm{NaY}^{8}$ No results were presented for diphenylamine in this series of studies.

The X-band EPR spectrum of triplet molecular oxygen in NaX zeolite has been observed to differ significantly from the spectrum in other condensed media. ${ }^{9}$ The peak normally found at $11.5 \mathrm{kG}$ from the perpendicular orientation and a broad parallel orientation feature extending to as low as $2 \mathrm{kG}^{10-12}$ are absent. What remains is a feature around $1600 \mathrm{G}$ which is about $90 \mathrm{G}$ in width. ${ }^{9}$ This transition is the consequence of a distortion that removes the axial symmetry of the electron distribution in $\mathrm{O}_{2}{ }^{9}$ This peak is attributed ${ }^{9}$ to an accompanying accumulation of intensity near the field of the forbidden triplet $\Delta \mathrm{m}_{\mathrm{s}}= \pm 2$ transition from $\mathrm{O}_{2}$ molecules nearly but not perfectly aligned with the magnetic field. The NO diatomic molecule is likewise known bind in similar fashion to the Lewis acid sites of ZSM5 zeolite. ${ }^{13}$

In recent studies, metal oxide and zeolite surfaces were treated with $\mathrm{H}_{2} \mathrm{O}_{2}$ and then thermally treated. ${ }^{14-16}$ The EPR spectra of a peroxy radical, of the $\mathrm{OH}$ radical and of an unrelated ground triplet state species were simultaneously observed. The peroxy radical, MOO, presumed to form at an M-centered Lewis acid site, had EPR parameters distinct from but similar in magnitude to $\mathrm{O}_{2}^{-}$. The $\mathrm{OH}$ radical was greatly stabilized chemically by the surfaces.

Oxidations of amines in solution are almost always performed with hydroperoxidic oxidizing agents and are very dependent on amine structure. Primary and secondary arylamines proceed through hydroxylamine intermediates, which are further oxidized by peroxide to nitroxides. The primary nitroxylamine can be further oxidized by peroxide to the nitrate. The nitroxide from secondary amine appears to be stable to further oxidation by peroxide. While the tertiary amine may go through a hydroxylamine-like intermediate, an amine-oxide is formed which undergoes no further peroxide oxidation. In the presence of tungstate catalysts, oxygen atoms from peroxide are thought to be stabilized in the tungstate. The peroxytungstate then oxidizes the amine to hydroxylamine and the hydroxylamine, in turn, to higher amine states of oxidation. 


\section{Experimental}

$\mathrm{Li}, \mathrm{Na}, \mathrm{K}, \mathrm{Rb}$ and $\mathrm{Cs}$ cation-exchanged X-zeolites were prepared from a stock of $\mathrm{Na}$ cation exchanged zeolite (Linde 13-X). The stock was maintained at constant humidity over saturated aqueous $\mathrm{HN}_{4} \mathrm{Cl}$. The exchanges were performed by agitating $2.5 \mathrm{~g}$ of zeolite in $25 \mathrm{ml}$ $10 \%(\mathrm{~W} / \mathrm{V})$ cation nitrate for $4 \mathrm{~h}$ at $90^{\circ} \mathrm{C}$. The exchanged zeolite slurry was vacuum filtered and rinsed with distilled, deionized water. The process was repeated four times. Then the zeolite was filtered and dried under $\mathrm{N}_{2}(\mathrm{~g})$ on filter paper and stored in the constant humidity cabinet until needed.

The zeolites were characterized by $\mathrm{x}$-ray diffraction, $\mathrm{x}$-ray elemental analysis and differential thermal analysis. The cubic unit cell parameter, $\mathrm{a}=25 \AA$ and the $\mathrm{Si} / \mathrm{Al}$ ratios were $\mathrm{Li}$ $\mathrm{X}: 1.34, \mathrm{Na}-\mathrm{X}: 1.34, \mathrm{~K}-\mathrm{X}: 1.43, \mathrm{Rb}-\mathrm{X}: 1.23$ and $\mathrm{Cs}-\mathrm{X}: 1.29$, consistent with an X-type faujasite and the degrees of exchange were $\mathrm{Li}: 99 \%, \mathrm{Na}: 99 \%, \mathrm{~K}: 91 \%, \mathrm{Rb}: \mathbf{7 3} \%$ and $\mathrm{Cs}: 58 \%$.

The zeolites were calcined on a vacuum line at $500^{\circ} \mathrm{C}$ until a pressure below $10^{-4}$ torr was achieved. The zeolite was retained in a cylindrical sample tube under a plug of glass wool while lowering the pressure and raising the temperature gradually. This was done in order to prevent the zeolite from exploding into the rest of the vacuum line while adsorbates were being released. Heat was provided by raising a cylindrical furnace around the sample tube on the vacuum line. The sample tube was flame-sealed, removed from the vacuum line and stored until use in a glovebox purged with prepure grade $\mathrm{N}_{2}(\mathrm{~g})$. The differential thermal analysis shows that relatively small amounts of water are released above $150^{\circ} \mathrm{C}$.

The zeolites were loaded with diphenylamine (Aldrich 99+\%) by adding $200 \pm 1 \mathrm{mg}$ of exchanged zeolite to $45 \mathrm{ml}$ of a $0.9 \mathrm{mM}$ solution of diphenylamine in hexane. These loading levels were based on a detailed diphenylamine loading study at various initial concentrations in $\mathrm{NaX}$ in which the absorbances of diphenylamine before and after loading were measured. The loading studies gave Freundlich isotherm parameters, $C_{1}=0.54 \pm 0.14$ and $C_{2}=1.30 \pm 0.008$. All of the zeolites were loaded at the initial molar diphenylamine-zeolite ratios that load $\mathrm{NaX}$ zeolite at 0.5 diphenylamine molecules per cage. The $\mathrm{KX}$ zeolite was loaded with aniline for comparison at the same initial molar ratio as diphenylamine. An attempt to load $\mathrm{KX}$ with triphenylamine was not successful to any appreciable extent as judged by the change in absorbance of the triphenylamine solution.

In order to investigate the fate of the diphenylamine amine proton, the $\mathrm{KX}$ zeolite was similarly doped with diphenyl- $d_{1}$-amine. The diphenylamine was exchanged with excess $D_{2} O$ in a custom-designed procedure to bring the diphenylamine into solution with $\mathrm{D}_{2} \mathrm{O}$. In this procedure, $0.2030 \mathrm{~g} \mathrm{DPA}$ and $1.2227 \mathrm{~g} \mathrm{D}_{2} \mathrm{O}$ (Bio-Rad, $99.8 \mathrm{~mole} \% \mathrm{D}$ ) were added together in a $50 \mathrm{~mL}$ round bottom flask (RBF). This amount of $\mathrm{D}_{2} \mathrm{O}$ corresponds to a 100 -fold molar excess of deuterons to protons for the amount of DPA used. Acetonitrile (Aldrich, 99.9 +\% HPLC grade) was added dropwise to the inhomogeneous mixture with gentle swirling until the mixture became transparent and homogeneous. An additional 10 drops of $\mathrm{CH}_{3} \mathrm{CN}$ were added along with a magnetic stir bar. A simple magnetic stirring apparatus was set up and a West condenser was attached to the RBF. The solution was stirred for 24 hours and transferred to a $250 \mathrm{~mL} \mathrm{RBF}$ 
with three $5 \mathrm{~mL} \mathrm{CH} \mathrm{CH}_{3}$ rinses. The resulting solution was evaporated at $310 \mathrm{~K}$ with a Buchi Model 111 Rotary Evaporator equipped with a water-heated bath for 30 minutes. The remaining clear liquid was transferred to a $125 \mathrm{~mL}$ separatory funnel and extracted three times with $10 \mathrm{~mL}$ portions of diethyl ether (J. T. Baker anhydrous ACS reagent grade). The ether extracts were collected in a clean dry $250 \mathrm{~mL} \mathrm{RBF}$ and evaporated at $315 \mathrm{~K}$ for 30 minutes. Almost immediately upon evaporation colorless crystals began to line the sides of the RBF. The crystals were transferred to a watch glass, dried in a desiccator for half an hour and then recrystallized from petroleum ether (b.p. $35-60^{\circ} \mathrm{C}$ ). The crystals were then transferred to a watch glass and placed in a $313 \mathrm{~K}$ oven to dry for 12 hours, transferred to a vial and placed into a $\mathrm{CaCl}_{2}$ desiccator for storage until needed. This procedure resulted in $0.1417 \mathrm{~g}$ of product, a $69 \%$ yield on a molar basis. The isotopic purity of the resulting sample was $77.6 \%$ diphenyl- $\mathrm{d}_{1}$-amine as determined by proton NMR analysis.

The loaded zeolite samples were dried on filter paper under a flow of $\mathrm{N}_{2}(\mathrm{~g})$ in the glove box and then about $80 \mathrm{mg}$ were transferred to EPR sample tubes. The EPR tubes were capped, removed from the glove-box and attached to the vacuum line. In order to remove adsorbed $\mathrm{N}_{2}$ and remaining solvent, the samples were pumped quickly to 1 mtorr, avoiding dopant removal by prolonged pumping. Then the EPR tubes of dried, pumped samples were flame sealed and removed from the vacuum line for EPR examination.

The samples were examined with a Varian V-4500 EPR spectrometer employing $100 \mathrm{kHz}$ field modulation, digital field control and digital data acquisition. The system has been described in a previous publication. 17 The temperature dependence of the EPR spectra of the samples between $5 \mathrm{~K}$ and room temperature was examined with an Oxford ITC 502 temperature controller and ESR-900 cryostat inserted into the rectangular TE102 cavity of the EPR spectrometer. Each magnetic field sweep was calibrated with a Micronow model 515-1 proton magnetic resonance gaussmeter probe. Microwave frequencies were measured with an Albia electronic counter, coupled with a Hewlett Packard Model 540B transfer oscillator.

\section{Experimental Results}

The EPR results comprise measurements of the peaks observed around the $g=2$ region of the spectrum, the peaks around the "half-field" region of the spectrum and an unsuccessful search for additional features of the triplet spectrum of which the "half-field" peak appears to be a part. The $\mathrm{g}=2$ and half-field peaks were studied as a function of temperature. Insofar as the temperature and the spectrometer power levels permitted unsaturated operation, quantitative intensity measurements were made relative to a sample of DPPH.

A comparison of typical measurements of the $g=2$ spectra in each of the cationexchanged $\mathrm{X}$ zeolites is shown in Figure 1. Note that the $\mathrm{KX}$ host gives the most intense spectrum. The half-field spectra are likewise shown in Figure 2, where again it is the KX host that leads to the more intense EPR spectrum. The background spectra are very small in comparison with the features in the KX spectra. However, the background spectra demonstrate that dopant-generated spectra in some of the cation-exchanged zeolites may be nearly negligible. 
The $\mathrm{g}=2$ spectra of $\mathrm{KX}$ treated with anoline, diphenylamine and triphenylamine are compared in Figure 3. The $g=2$ spectra resulting from doping the cation-exchanged $X$ zeolites with diphenyl$\mathrm{d}_{1}$-amine is shown in Figure 4.

\section{Analysis and Results}

The $g=2$ spectra, having the general appearance of a randomly-oriented ${ }^{14} \mathrm{~N}$ hyperfine triplet with some $\mathrm{g}$ anisotropy were fitted to the spin Hamiltonian parameters in Equation 1 and to the anisotropic rotational correlation times by the method of Freed. 18 The parameters obtained

$$
\mathrm{H}=\beta_{\mathrm{e}} H \cdot \mathrm{g} \cdot \mathrm{S}+\mathrm{S} \cdot \mathrm{A} \cdot \mathrm{I}
$$

at $293 \mathrm{~K}$ are given in Table 1 . The spectra at $5 \mathrm{~K}$ are fit by parameters that are the same as $293 \mathrm{~K}$ within experimental error. However, the simulation did not always fully reproduce what appears to be another spectrum at $\mathrm{g}=2.004$. A difference spectrum between the experimental spectrum and the simulated spectrum is shown in Figure 4. It's position is similar to the $\mathrm{g}_{x x}, \mathrm{~g}_{\mathrm{yy}}$ observed for $\mathrm{O}_{2}{ }^{-}$or peroxy radicals in similar systems. ${ }^{14-16}$ We have not been able to detect the weak $\mathrm{g}_{\mathrm{zz}}$ peak associated with $\mathrm{O}_{2}^{-}$or the peroxy radical. ${ }^{-14-16}$ The spin Hamiltonian parameters are in excellent agreement with those of diphenylnitroxide, ${ }^{19}$ also given in Table 1 . The measured halffield peak position was determined from the average of several measurements in samples of diphenylamine in $\mathrm{KX}$ at $5 \mathrm{~K}$. The position, interpreted as the low-field extreme of the $\Delta \mathrm{m}_{\mathrm{s}} \pm 2$ transition of a triplet state powder pattern is found at a field from which the value of $\sqrt{\mathrm{D}^{2}+3 \mathrm{E}^{2}}$ may be determined according to Equation 2.20

$$
\mathrm{D}^{2}+3 \mathrm{E}^{2}=\left[\left(\frac{\mathrm{h} v}{2}\right)^{2}-(\mathrm{g} \beta \mathrm{H})^{2}\right]
$$

The parameters $\mathrm{D}$ and $\mathrm{E}$ are the longitudinal and transverse anisotropic fine structure interaction parameters in the triplet state spin Hamiltonian. ${ }^{12}$ The analysis gives $\sqrt{\mathrm{D}^{2}+3 \mathrm{E}^{2}} / \mathrm{h}=$ $3360 \pm 420 \mathrm{MHz}$. The uncertainty is the average width of the rise from the baseline to the peak of the integrated spectrum, which would be a discontinuous rise in the absence of line broadening effects. The spectrum-to-spectrum variation in the position of the rise was neglected in determining the uncertainty. If the system giving rise to this value is interpreted a $\mathrm{s}$ a pair of interacting point magnetic dipoles (electrons) separated by a distance $r_{12}(E=0)$, then Equation $3^{20}$ can be solved.

$$
D=1 / 2 g^{2} \beta^{2} e^{r^{2}{ }^{2}-3 z^{2}} \frac{12}{r_{12}{ }^{5}}
$$

for $\mathrm{v}^{12}=2.50 \pm 0.30 \AA\left(\mathrm{r}_{12}=\left|\mathrm{z}_{12}\right|\right)$. 
The $\mathrm{g} \approx 2$ and half-field first derivative EPR spectra from the samples of diphenylamine in the series of cation-exchanged zeolites were doubly integrated and corrected for sample size, modulation amplitude and receiver gain. In Table 2 are given the relative intensities of the $g \approx 2$ peaks measured at $293 \mathrm{~K}$ and the relative intensities of the half-field peaks measured at $5 \mathrm{~K}$ but corrected to $293 \mathrm{~K}$ with the corresponding ratio of Boltzmann factors.

\section{Discussion}

We propose that the oxidation of diphenylamine to diphenyl nitroxide begins with Lewis acid sites which have previously been proposed to form from Bronsted acid sites upon calcining under vacuum. It is natural to expect that like analine and triphenylamine, ${ }^{7,8}$ these sites are capable of accepting an electron from diphenylamine to form the cation radical.

We further propose, that like the study of analine, ${ }^{8}$ when the system is exposed to $\mathrm{O}_{2}$, the $\mathrm{O}_{2}$ is stabilized in the form of $\mathrm{O}_{2}^{-}$or peroxyradical at these Lewis acid sites, as depicted in Figure 5 and in agreement with one of the peaks in the observed spectrum.

In the oxidation of organic hydrocarbon molecules in zeolite cages, the cation radicals usually act as Bronsted acids in the presence of $\mathrm{O}_{2}^{-}$(forming organic peroxides). ${ }^{1-4}$ If we suppose that the transition state shown in Figure 6 is formed between the diphenylamine cation and the zeolite-stabilized $\mathrm{O}_{2}^{-}$, oxidation to diphenylnitroxide is facilitated by proton donation. By diphenylamine cation and subsequent cleavage. Interestingly the proposed scheme generates the elusive $\mathrm{OH}$ radical which under normal conditions would form peroxide. We note, as also shown in Figure 6, that the Lewis acid site appears to be an ideal one for stabilizing the $\mathrm{OH}$ radical. The model is similar to the one presented for the oxidation of several alkenes at oxidation sites in mordenite. ${ }^{21}$

\section{References}

1. F. Blatter and H. Frei, J. Am. Chem. Soc. 116, 1812 (1994).

2. H. Sun, F. Blatter and H. Frei, J. Am. Chem. Soc. 116, 7951 (1994).

3. H. Sun, F. Blatter and H. Frei, J. Am. Chem. Soc. 118, 6873 (1996).

4. F. Blatter, H. Sun and H. Frei, Chem. Eur. J., 2, 385 (1996).

5. K. B. Yoon and J. Kochi, J. Am. Chem. Soc., 110, 6586 (1988).

6. K. B. Yoon, Chem. Rev.93, 321(1993).

7. D. N. Stamires and J. Turkevich, J. Am. Chem. Soc. 86, 749 (1964).

8. F. R. Chen and J. J. Fripiat, J. Phys. Chem. 96, 819 (1992).

9. H. Kon, J. Am. Chem. Soc. 95, 1045 (1973).

10. J. Vedrine, in E. Deronene, F. Lemos, C. Naccache and F. Ribeiro (Eds) "Zeolite Microporous Solids: Synthesis, Structure and Reactivity," NATO ASI Series C, vol. 352, Kluwer Academic Publishers

11. R. Simonean, J. S. M. Harvey and G. M. Graham, J. Chem. Phys. 54, 4819 (1971). 
12. W. Weltner, "Magnetic Atoms and Molecules," Scientific and Academic Editions, New York, 1983.

13. A. Gutsze, M. Plato, H. G. Karge and F. Witzel, J. Chem. Soc. Faraday Trans. 92, 2495 (1996).

14. E. Giamello, L. Calosso, B. Fubini, and F. Geabaldo, J. Phys. Chem. 91, 5735 (1993).

15. E. Giamello, P. Rumori, B. Fubini, and M. C. Paganini, Appl. Magn. Reson. 10, 173 (1996).

16. B. D’Anna and E. Giamello, Appl. Magn. Reson. 10, 591 (1996).

17. D. C. Doetschman, D. W. Dwyer, J. D. Fox, C. K. Frederick, S. Scull, G. D. Thomas, S. G. Utterback and J. Wei, Chemical Physics, 185, 343 (1994).

18. J. H. Freeed in: Spin labeling; theory and applications, ed. L. J. Berliner (Academic Press, New York, 1976), p. 53.

19. T.-S. Lin, J. Chem. Phys. 57, 2260 (1972).

20. A. Carrington and A. D. McLachlan, "Introduction to Magnetic Resonance," Wiley, New York, 1979.

21. G. Harvey, R. Prins, R. Crockett and E. Roduner, J. Chem. Soc., Faraday Trans. 92, 2027 (1996). 
Table 1. Results of the best fit ${ }^{18}$ of the spectrum simulation to the $\mathrm{m}_{\mathrm{I}}= \pm 1$ features of the diphenylnitroxide spectra in diphenylamine (DPA) doped K-X zeolite at $5 \mathrm{~K}$ and $293 \mathrm{~K}$. The literature values ${ }^{19}$ are also presented for comparison. Uncertainties are given in parentheses.

\begin{tabular}{|lccc|}
\hline Parameter & DPA (5K) & DPA (293K) & DPA (Lit. $\left.{ }^{19}\right)$ \\
\hline $\mathrm{A}_{\mathrm{xx}}(\mathrm{G})^{(\mathrm{a})}$ & $4.2(0.5)$ & $4.2(0.4)$ & $1.9(0.2)$ \\
$\mathrm{A}_{\mathrm{yy}}(\mathrm{G})^{(\mathrm{a})}$ & $8.1(0.5)$ & $4.1(0.4)$ & $3.6(0.2)$ \\
$\mathrm{A}_{\mathrm{zz}}(\mathrm{G})^{(\mathrm{a})}$ & $27.5(0.5)$ & $27.9(0.2)$ & $23.8(0.2)$ \\
$\mathrm{g}_{\mathrm{xx}}(\mathrm{a})$ & $2.0091(0.0003)$ & $2.0091(0.0003)$ & $2.0092(0.0001)$ \\
$\mathrm{g}_{\mathrm{yy}}(\mathrm{a})$ & $2.0045(0.0003$ & $2.0045(0.0003)$ & $2.0056(0.0001)$ \\
$\mathrm{g}_{\mathrm{zz}}(\mathrm{a})$ & $2.0016(0.0003)$ & $2.0091(0.0003)$ & $2.0022(0.0001)$ \\
$\mathrm{d}_{\mathrm{xy}}{ }^{(b)}\left(\mathrm{sec}^{-1}\right)$ & $1.0 \times 10^{3}$ & $6.0 \times 10^{5}$ &.-- \\
$\mathrm{d}_{\mathrm{zz}}\left(\mathrm{sec}^{-1}\right)$ & $8.0 \times 10^{6}$ & $8.0 \times 10^{5}$ & \\
$\mathrm{~g} \beta \Delta \Delta \mathrm{H} / \mathrm{h}^{\left(\mathrm{sec}^{-1}\right)}$ & & & \\
\hline
\end{tabular}

(a) The $\mathrm{z}$ axis is parallel to the $\mathrm{p}$ orbital directions of the NO $\pi$ system, the $\mathrm{x}$ axis is parallel to the NO bond and the $y$ axis is perpendicular to both the $\pi$ system p orbitals and the NO bond.

(b) Rotational diffusion constants perpendicular ( $x y)$ and parallel (zz) to the p orbital directions of the NO $\pi$ system.

(c) Homogeneous linewidth in the absence of rotational diffusion. 
Table 2. Relative integrated intensities at the same temperature of the spectra observed in diphenylamine and diphenylamine- $\mathrm{d}_{1}$ doped cation-exchanged zeolites, $\mathrm{Li}-, \mathrm{Na}-, \mathrm{K}-, \mathrm{Rb}-$ and $\mathrm{Cs}-$ $\mathrm{X}$.

\begin{tabular}{|c|c|c|c|c|c|}
\hline Zeolite & Dopant & DPNO$^{(a)}$ & Residue(b) $^{(b)}$ & $\operatorname{Sum}^{(c)}$ & Half-field \\
\hline \multirow[t]{2}{*}{$\mathrm{Li}-\mathrm{X}$} & DPA & - & - & 0.52 & 1.34 \\
\hline & $\mathrm{d}_{1}$-DPA & - & - & 3.84 & 0 \\
\hline \multirow[t]{2}{*}{$\mathrm{Na}-\mathrm{X}$} & DPA & -- & -- & 2.30 & 0.28 \\
\hline & $\mathrm{d}_{1}-\mathrm{DPA}$ & -- & -- & 3.02 & 3.32 \\
\hline \multirow[t]{2}{*}{$\mathrm{K}-\mathrm{X}$} & DPA & 5.72 & 2.46 & 8.19 & 3.48 \\
\hline & $\mathrm{D}_{1}$-DPA & 5.86 & 1.22 & 7.08 & 4.70 \\
\hline \multirow[t]{2}{*}{$\mathrm{Rb}-\mathrm{X}$} & DPA & -- & -- & 0.90 & 1.30 \\
\hline & $\mathrm{d}_{1}-\mathrm{DPA}$ & -- & -- & 0.42 & 2.68 \\
\hline \multirow[t]{2}{*}{$\mathrm{Cs}-\mathrm{X}$} & DPA & -- & - & 0 & 0.36 \\
\hline & $\mathrm{d}_{1} \mathrm{DPA}$ & - & -- & 4.12 & 0.50 \\
\hline
\end{tabular}

(a) Diphenylnitroxide best fit.

(b) Difference spectrum, experimental spectrum minus simulated diphenylnitroxide spectrum.

(c) Sum of DPNO plus residue equals experimental spectrum. 


\section{FIGURE CAPTIONS}

(original figures are with the publisher and copies are not available)

1. CW-EPR spectra acquired at $293 \mathrm{~K}$ of the $\mathrm{g}=2$ region obtained from diphenylamine doped into the series of alkali metal cation-exchanged zeolites, $\mathrm{Li}-, \mathrm{Na}-, \mathrm{Rb}-$, and $\mathrm{Cs}-\mathrm{X}$.

2. CW-EPR spectra acquired at $5 \mathrm{~K}$ of the half-field region obtained from diphenylamine doped into the series of alkali metal cation-exchanged zeolites, $\mathrm{Li}-, \mathrm{Na}-, \mathrm{K}-, \mathrm{Rb}-$, and $\mathrm{Cs}-\mathrm{X}$.

3. CW-EPR spectra acquired at $293 \mathrm{~K}$ of the $\mathrm{g}=2$ region obtained from analine (MPA) and diphenylamine (DPA) doped into K-X zeolite. In the case of the triphenylamine/K-X spectrum, the adsorption is particle surface adsorption, as insignificant loading of zeolite cages occurred.

4. CW-EPR spectra acquired at $293 \mathrm{~K}$ of the $\mathrm{g}=2$ region obtained from diphenylamine- $\mathrm{d}_{1}$ doped into the series of alkali metal cation-exchanged zeolites, $\mathrm{Li}-, \mathrm{Na}-, \mathrm{K}-, \mathrm{Rb}-$, and $\mathrm{Cs}-\mathrm{X}$.

5. Diagram illustrating the proposed Lewis acid sites formed in faujasite zeolites upon thermal activation in the presence of oxygen and the formation of $\mathrm{O}_{2}{ }^{-}$and transient diphenylamine cation.

6. The proposed transition state and resultant products for the oxidation of diphenylamine to diphenylnitroxide on K-X faujasite zeolite. 


\section{Diphenylamine With Li- Thru Cs-X Zeolites}

\section{$293 \mathrm{~K},-20 \mathrm{~dB}$ CW-ESR Spectra}

4

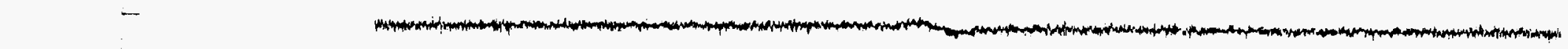

2

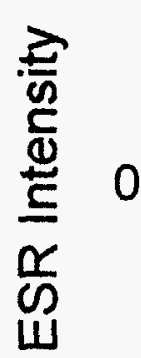

$-2$
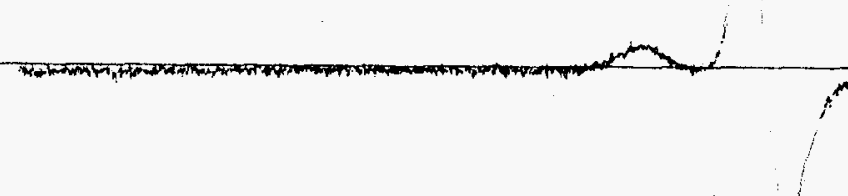

$-4$

3100

3200

3300

3400

Magnetic Field Strength (Gauss)

$\begin{array}{llll}-\mathrm{Li}-\mathrm{X} & -\mathrm{Na}-\mathrm{X} & \mathrm{K}-\mathrm{X} & \mathrm{Rb}-\mathrm{X}\end{array}$




\section{Diphenylamine With Li- Thru Cs-X Zeolites}

$5 \mathrm{~K},-20 \mathrm{~dB}$ CW-ESR Spectra, half-field peaks

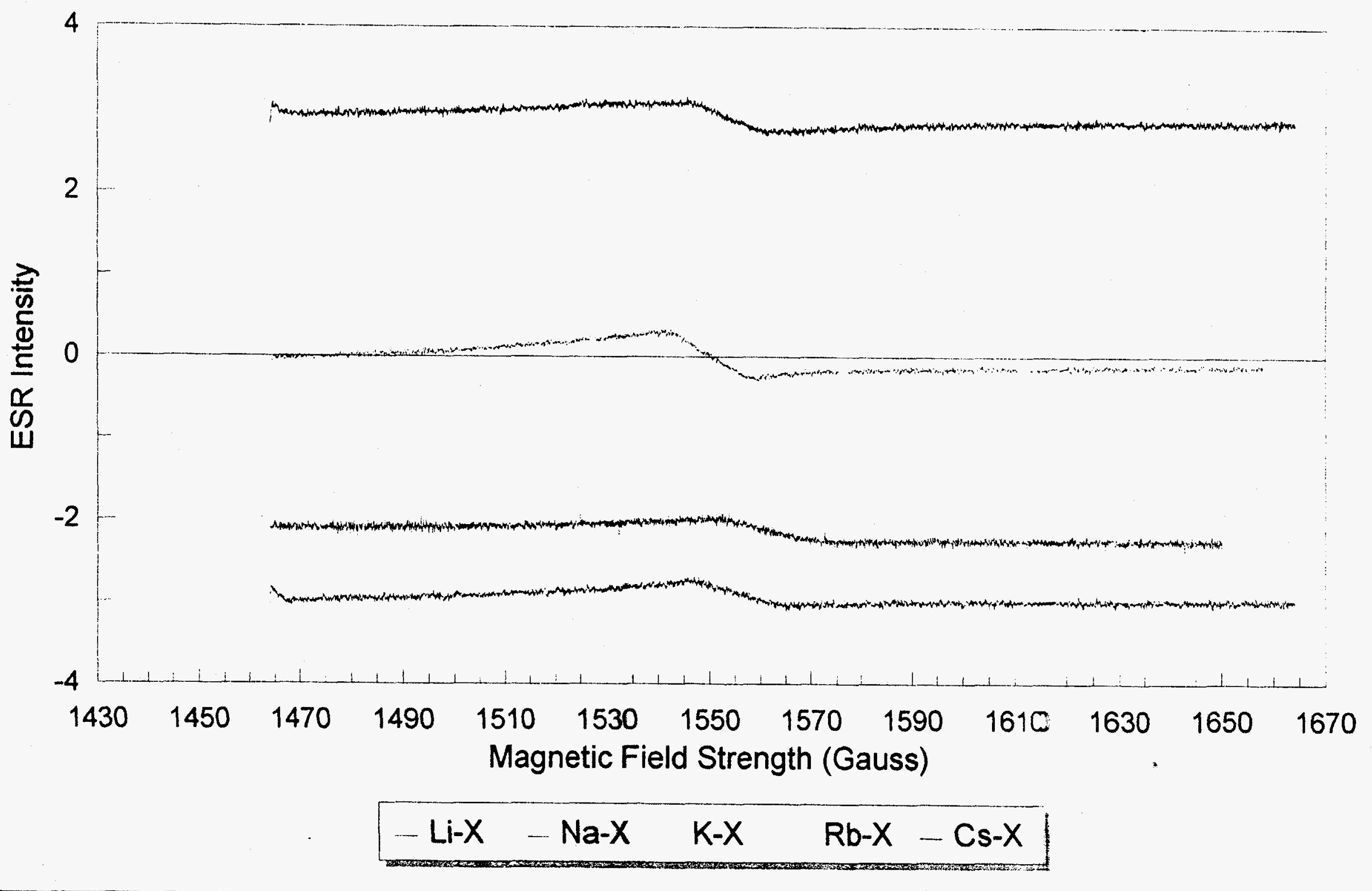




\section{MPA, DPA and TPA in K-X Zeolite}

$294 \mathrm{~K},-20 \mathrm{~dB}$ CW-ESR Spectra

3

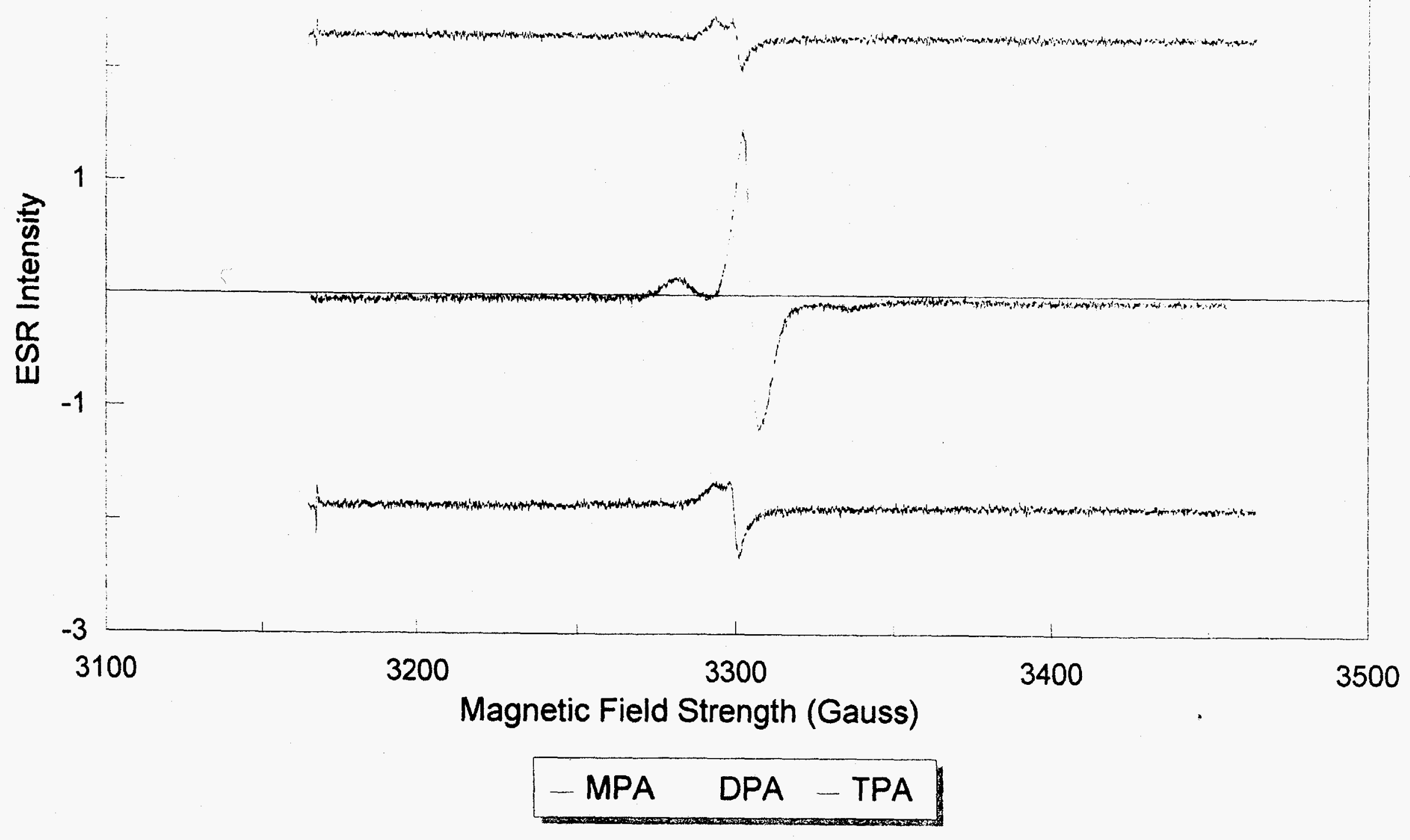




\section{d-1-Diphenylamine With Li- Thru Cs-X Zeolites}

\section{K, -20dB CW-ESR Spectra}

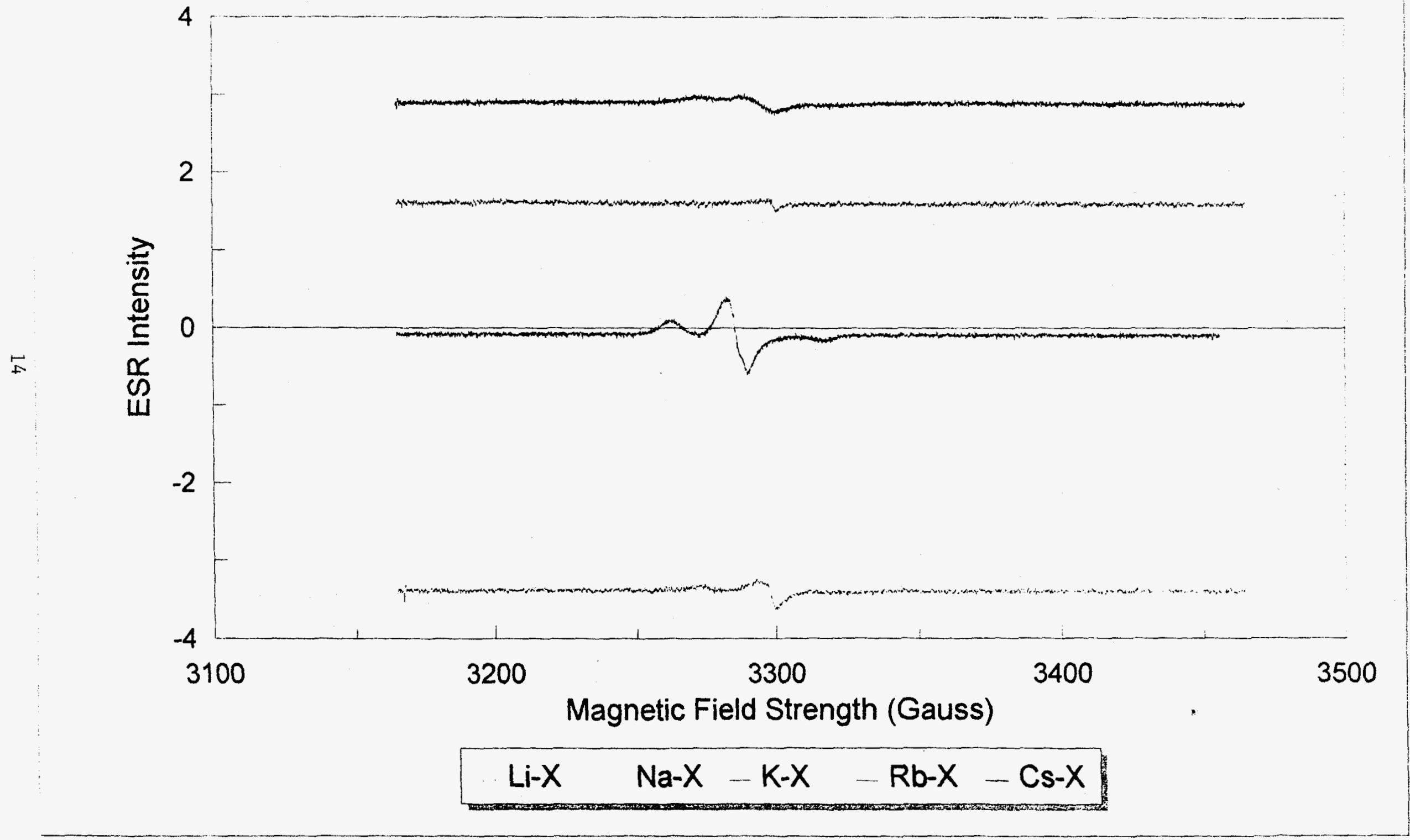



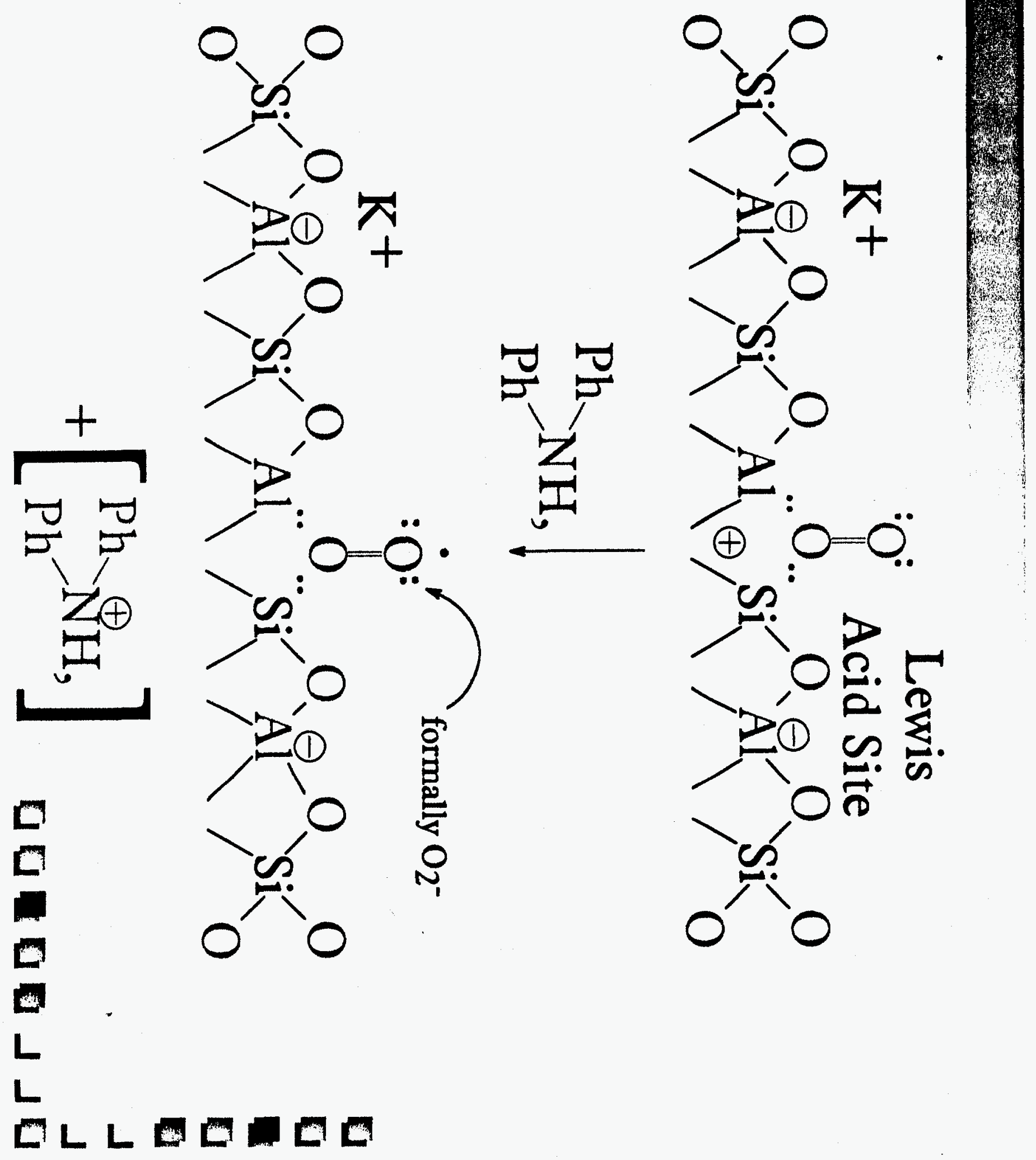


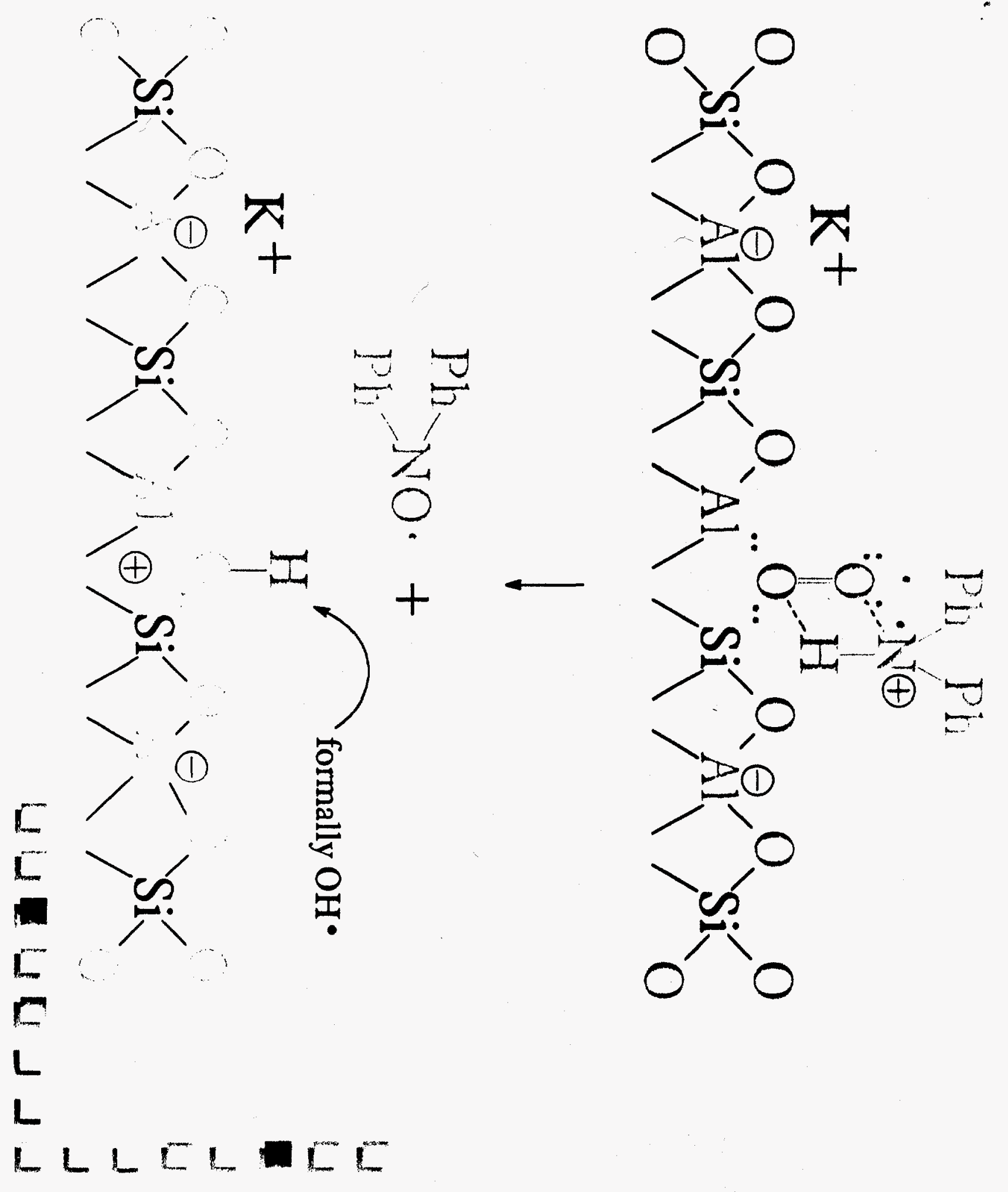

